\title{
Adaptation in Transition
}

$\mathrm{O}$ ne year ago I wrote my first editorial in Ecological Restoration on behalf of the Society for Ecological Restoration International (SERI). We had just completed a very successful World Restoration Conference at a joint meeting with the Ecological Society of America (ESA). At this meeting the SERI board of directors approved our 2007-2012 strategic plan, which requires us to become more involved in informing legislation and policymakers as well as to expand our international scope, while at the same time addressing the needs of North American practitioners through the development of a certification program and other mechanisms. Consistent with our strategic plan, we released our first SERI policy position statement on how ecological restoration can help mitigate global climate change; this statement was endorsed by the ESA board of directors.

The end of 2008 gives us the chance to reflect on some of the important changes and accomplishments that have occurred within SERI in the past year. One of the most important was the resignation of long-time SERI Executive Director Mary Kay LeFevour and a restructuring of the SERI main office. Mary Kay served the Society with dedication, helping us to become fiscally stable and, among many other accomplishments, launching the Global Restoration Network (GRN). A new Executive Director search is being conducted and the relocation of our headquarters to the U.S. East Coast is being considered. SERI Project Director Sasha Alexander is currently working from New York. Our GRN intern Levi Wickwire and numerous board members have jumped in to assist during this time of transition.

SERI has now begun to take advantage of many new and exciting opportunities around the world. In addition to the climate change document, the Science and Policy Working Group issued a Briefing Note on the relationship between conservation and ecological restoration, which was released at the United Nations World Conference on Biological Diversity held in Bonn, Germany. A Policy Position Statement on ecosystem fragmentation was released at the most recent IUCN World Conservation Congress in Barcelona, Spain, during which several SERI board members participated in sessions with the IUCN Commission on Ecosystem Management and Parks Canada.

Ecological Restoration Vol. 26, No. 4, 2008

ISSN 1522-4740 E-ISSN 1543-4079

(O2008 by the Board of Regents of the University of Wisconsin System.
Sasha staffed our exhibit, and both he and I attended the meeting of the members. Earlier in the year, several SERI board members also attended an invitation-only meeting at the Royal Botanic Gardens, Kew, in order to assist Kew in developing a restoration ecology program and to determine how botanic gardens can assist with the study and implementation of restoration projects.

Back in North America, much work has been done on the SERI Professional Certification Program, which is scheduled for launch in late 2009. This program will offer professionals and practitioners an important recognition of their qualifications and competence in the science and practice of ecological restoration. It will serve to enhance the visibility of both experienced individuals and the proven methods and techniques of practicing ecological restoration. The program will also meet the increasing demand for validation and standards among public and private agencies engaged in restoration activities.

We also laid the foundation for a number of innovative projects and programs that build and expand upon SERI's original mission. In August, the SERI Board approved our first collaborative Restoration Resource Center (RRC), which will be hosted in South Korea by the Korea Eco-City Network. This is the first of many RRCs that will disseminate information on SERI and ecological restoration to organizers and volunteers in local communities. We also received a grant to begin developing a Community Restoration Network, which is being proposed as a new vehicle to help us fulfill our core mission-reestablishing a healthy relationship between nature and culture. The intent of this program is to empower individuals and communities by providing the tools, expertise, and access to information necessary to restore nature and sustain healthy livelihoods. The primary beneficiaries of the Community Restoration Network will be local communities-individuals and groups coming together to restore habitats and ecosystems, including private landowners, public land trusts, and NGOs that are increasingly getting involved in local restoration efforts. The Community Restoration Network will be an invaluable resource for volunteer coordinators, public-private partnerships, and nonprofit project/event managers within the emerging land-connection movement. Access to science-based principles and guidelines for developing and implementing an effective restoration project would greatly assist those coordinating and guiding efforts within local communities. 
Looking ahead, our 2009 World Restoration Conference will be held in Perth, Australia. Our hosts are SERI board member Kingsley Dixon and the world famous Kings Park and Botanic Garden. This past November we participated in the Mexican Congress of Ecology, where we continued to develop contacts in Latin America. Kingsley, Sasha, and 2005 conference chair Francisco Comín are working together in the hope that we can have our first World Restoration Conference in Latin America in 2011. We have already cultivated partnerships with a number of organizations and networks in Latin America and the Caribbean, which we hope will result in an exciting and highly successful meeting. In keeping with our global outreach, we are now exploring the possibility of holding our 2013 World Conference in Africa or Asia.

Finally, a word on SERI leadership. Over the last 15 years, I have had the opportunity to work with some really amazing and dedicated people and SERI has been very fortunate in the leaders it has attracted. And I must say that the current board is one of the best I have served with. But as some of you know, getting someone to agree to lead a large society on a volunteer basis can sometimes be quite a challenge. I am happy to report that this August,
Jim Harris, a ten-year veteran of the SERI Board was selected as Chair-elect to the Society. Jim is a professor and Chair in Environmental Technology at Cranfield University in the UK. Jim will serve as vice chair through the end of the 2009 meeting at Perth, when his two-year term as chair of the board will begin. He is currently chair of SERI's Science and Policy Working Group and serves on the Executive Committee. Jim will be the first SERI board chair from outside of North America and his selection cements our commitment to be a fully functional international society.

I want to personally thank everyone who has worked to make SERI a leader in the global environmental field and also those who have helped us keep our noses to the ground in local communities in North America and elsewhere. I encourage you to keep abreast of our activities and as always look forward to your input and participation.

Yours truly, George Gann, Chair Society for Ecological Restoration International 